\title{
Towards a whole-network risk assessment for railway bridge failures caused by scour during flood events
}

\author{
Rob Lamb ${ }^{1,2, a}$, Raghav Pant ${ }^{3}$, and Jim Hall ${ }^{3}$ \\ ${ }^{1}$ JBA Trust, South Barn, Broughton Hall, Skipton, BD23 3AE, UK \\ ${ }^{2}$ Lancaster Environment Centre, University of Lancaster, LA1 4YQ, UK \\ ${ }^{3}$ Environmental Change Institute, University of Oxford, Oxford, UK
}

\begin{abstract}
Localised erosion (scour) during flood flow conditions can lead to costly damage or catastrophic failure of bridges, and in some cases loss of life or significant disruption to transport networks. Here, we take a broad scale view to assess risk associated with bridge scour during flood events over an entire infrastructure network, illustrating the analysis with data from the British railways. There have been 54 recorded events since 1846 in which scour led to the failure of railway bridges in Britain. These events tended to occur during periods of extremely high river flow, although there is uncertainty about the precise conditions under which failures occur, which motivates a probabilistic analysis of the failure events. We show how data from the historical bridge failures, combined with hydrological analysis, have been used to construct fragility curves that quantify the conditional probability of bridge failure as a function of river flow, accompanied by estimates of the associated uncertainty. The new fragility analysis is tested using flood events simulated from a national, spatial joint probability model for extremes in river flows. The combined models appear robust in comparison with historical observations of the expected number of bridge failures in a flood event, and provide an empirical basis for further broad-scale network risk analysis.
\end{abstract}

\section{Introduction}

Scour is widely regarded as a common cause of failure in bridges that cross rivers [1, 2]. Between 1846 and 2013, 100 railway bridge failures (Figure 1) have been linked to scour during flood events in Britain [3,4], leading to fatalities as well as monetary losses.

Models exist to estimate the depth of scour at a structure (for example, see [1-2, 5-8]). However, there remain substantial uncertainties about whether one or more failures may occur across an infrastructure network during flood events. This uncertainty is reflected in a wide range of flood event magnitudes that have been observed in association with failure events [3,4].

Therefore, we adopt a probabilistic approach here, using the historical failure data in [4] to construct empirical fragility functions for a generic "GB rail bridge" that express the probability of failure conditional on a loading term related to flood event severity.

\section{Data}

The railway network grew from the 1840 s until a dramatic contraction in the 1960s (Figure 1, [9-11]).

\footnotetext{
a Corresponding author: rob.lamb@jbatrust.org
}

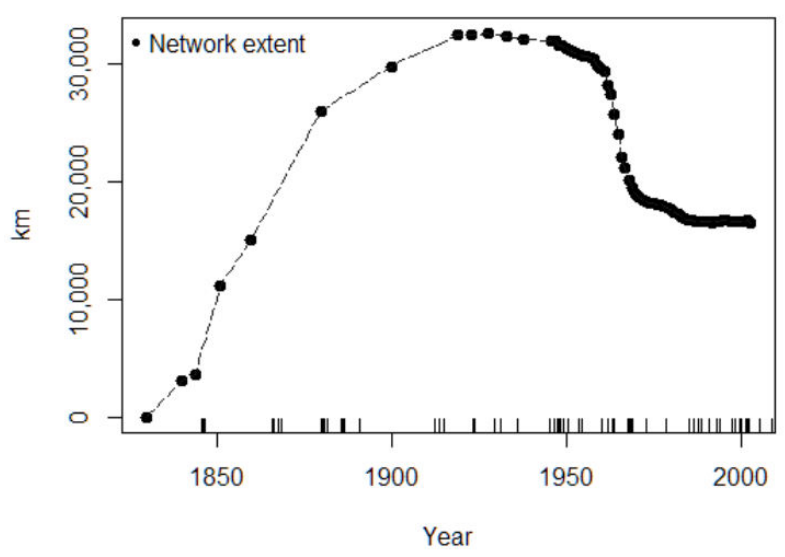

Figure 1. Solid dots show extent of rail network in Britain. Tick lines at bottom of plot show dates of scour-related bridge failures.

National infrastructure asset data was analysed in conjunction with floodplain maps [12] to identify 8,877 bridges that cross rivers and their floodplains in Great Britain. This is a contemporary snapshot of the network, which could give rise to a bias in failure probability estimates based on historical data alone. To counter this potential bias, we will adjust historical failure rates in the 
following section according to the ratio between the mean historical network extent and its contemporary extent, $\gamma=$ $22,291 \mathrm{~km} / 16,493 \mathrm{~km} \approx 1.35$.

For 51 of the bridge failures shown in Figure 1, there have been assessments made [4] of the relative magnitude $y_{i}$ of the flood associated with the $i^{\text {th }}$ failure, expressed in terms of a return period in units of years (i.e. the reciprocal of the annual exceedance probability). For the remaining failures, we estimated the most severe flood event, $y_{i}{ }^{*}$, encountered at the bridge location $i$ over a representative historical period by interpolation of flow records from nearby river flow gauges, using data from the UK National River Flow Archive (NRFA) (http://nrfa.ceh.ac.uk/) and an interpolation scheme documented and tested in [13].

\section{Fragility analysis}

\subsection{Fragility function}

We chose to apply a lognormal fragility function to describe the probability of failure conditional on a flood event,

$$
\operatorname{Pr}(\text { failure } \mid y)=F(y)=\Phi\left(\frac{\ln (y / \theta)}{\beta}\right)
$$

where $y$ is the return period of the flood event associated with a failure, $\varphi($.$) is the standard normal distribution$ function, $\theta$ is a location parameter and $\beta$ is a dispersion parameter, and

$$
F(y)=\int_{y} f(y) d y=\int_{y} \varphi\left(\frac{\ln (y / \theta)}{\beta}\right)
$$

where $\varphi($.$) is the standard normal density function. The$ lognormal distribution was considered an appropriate choice for reasons discussed by [14]. Although other distributional assumptions could be tested, our results did not suggest any obvious reason to reject the lognormal form.

\subsection{Inference}

We estimated the parameters $\theta$ and $\beta$ by maximising a likelihood function with respect to the historical bridge failure data. We treated each failure event as an independent observation. Lacking detailed information about the repair of damaged bridges, we have not accounted for their possible reinstatement. Since very few bridges have ever failed (relative to the entire population), we consider this to be a relatively small source of uncertainty.

The likelihood function is
$L(\Theta)=$
$\prod_{i \in \Delta}\left[f\left(y_{i} ; \Theta\right)\right]^{\delta_{A}(i)}\left[F\left(y_{i}^{*} ; \Theta\right)\right]^{\delta_{B}(i)}\left[1-F\left(y_{i}^{*} ; \Theta\right)\right]^{\left(\gamma \delta_{C}(i)\right)}$

where an indicator variable $\delta(i)$ is utilised to introduce information from three subsets of bridges as follows:

$\delta_{A}(i)=1 ; \delta_{B}(i)=0 ; \delta_{C}(i)=0$ for bridges known to have failed with an estimated flood return period for the failure event (subset A),

$\delta_{A}(i)=0 ; \delta_{B}(i)=1 ; \delta_{C}(i)=0$ for a bridges known to have failed where the flood return period of the failure event is undocumented and a maximum flood of record has been inferred (subset B),

$\delta_{A}(i)=0 ; \delta_{B}(i)=0 ; \delta_{C}(i)=1$ for bridges that have not failed, represented by the contemporary network (subset C) with additional power $\gamma$ introduced to adjust for the average historical network extent being larger than the contemporary network, under an assumption that the average number of bridges per kilometre of network length has not changed significantly.

The parameters in equation (3) are $\Theta=\{\theta, \beta\}$ and $\Delta$ is the set of all observations, combining bridge failures and surviving bridges.

Equation (3) was transformed to the log-likelihood, which we maximised by evaluating trial grids of 250,000 values of $\theta$ and $\beta$ to identify broadly the region containing the maximum, followed by optimisation [15] to obtain the final estimates $\theta^{*}$ and $\beta^{*}$. The $95 \%$ confidence region around $\theta^{*}$ and $\beta^{*}$ is then approximated by

$$
2\left[\ln L\left(\theta^{*}, \beta^{*}\right)-\ln L(\theta, \beta)\right] \leq \chi_{\alpha}^{2}
$$

where $\alpha=.05$ is the confidence level [16].

\subsection{Results}

Fragility functions derived using the procedure described in Section 3.2 are shown in Figure 2. Two variants are shown, as follows:

- A solid curve representing a function inferred from the full likelihood (equation 3), which includes information from all bridge failures (subsets A, B and C) and also the large subset of bridges that have not failed.

- A function inferred from only the subset of 51 bridge failures (subset A, dashed curve) for which we have documentary evidence of the return period of the associated flood event.

The failure observations in subset $\mathrm{A}$ are plotted in Figure 2. These points have been jittered slightly so as to display the full subset because the flood return period 
estimates in [4] were heavily rounded, and therefore many of individual values would otherwise plot on top of each other.

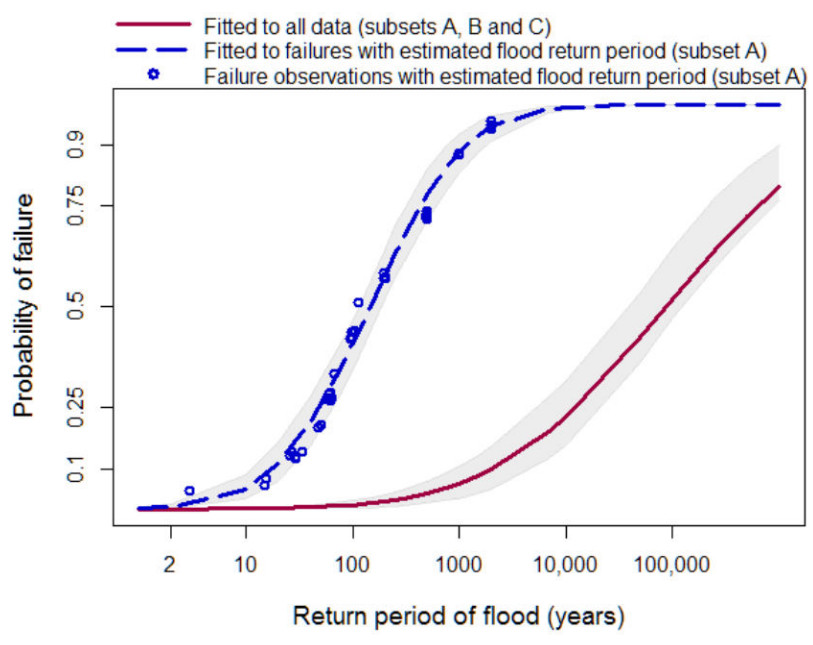

Figure 2. Bridge failure fragility functions with shaded confidence regions.

The points and the dashed line represent a conditional analysis of the subset of bridges that have all failed after a flood of a "known" return period. We estimated the failure probability of each of these "observations" using its Weibull plotting position, evaluated from the rank of the associated flood event (ranked in terms of the return period).

This analysis implies that the most extreme of the historical floods corresponds to a failure probability of close to one for the bridges in subset $\mathrm{A}$, and permits some conditional validation of the fragility function fitted by using the first term in equation (3), i.e. the dashed line, which agrees well with the failure data.

Clearly by conditioning our fragility analysis only on the small subset of 51 bridge failures in subset $\mathrm{A}$, we would greatly underestimate the general failure probability of a bridge given that only 100 failures have been observed within the full set of all bridges, currently numbering 8,877 (and presumed to have an effective cardinality of $8,877 \times \gamma$ to account for the historical growth of the network).

Unsurprisingly, we find that after introducing the relatively large number of surviving bridges (subset $C$, third term in equation 3 ) the fragility function shifts to the right in Figure 2, that is the failure probability conditional on a specified flood event is much lower than if we analyse only the subset of bridges that have failed.

The introduction of subset B (the bridge failures that do not have a detailed flood return period assessment, also included in the solid curve shown in Figure 2) slightly counter-balances the effect of the surviving bridges. However, the contribution to the likelihood from the 100 bridge failures is dominated by the much larger number of surviving bridges.

\section{Reliability analysis}

\subsection{Simulated flood event model}

A new probabilistic method for modelling spatially coherent river flood events was introduced by [13], using asymptotically justified models developed by [17] for the conditional distribution of a set of variables, given that one variable exceeds a threshold. We applied the same methods as [13], fitting the model to the NRFA flow data. We applied the Monte Carlo Simulation (MCS) procedure proposed by [18] to generate a large sample of possible flood events over the rail network. This sample includes some events more extreme than any observed in the past.

\subsection{Comparison with observed failure rates}

The 100 bridge failures in Figure 1 were associated with 54 flood events. The mean number of failures per event, conditional on having observed at least one failure, is $\mu=100 / 54 \approx 1.85$, with a $95 \%$ confidence interval

$$
\mu_{N \mid n>0} \pm 1.96 s=(1.34,2.38)
$$

where $\mathrm{s}=\sigma_{\mathrm{A} \cup \mathrm{B}} / 54^{(1 / 2)}=0.23$ is the standard error of the mean.

We sampled 1,000 sets of 54 simulated, spatially coherent flood events from the MCS discussed above and applied the spatial interpolation procedure of [13] to construct estimates of the corresponding flows at bridges.

The probability of encountering one or more bridge failure in any simulated event $j$ is the complement of the joint probability of no bridges failing, or

$$
\operatorname{Pr}\left(n^{j}>0\right)=1-\left[\prod_{k \in \Delta} 1-F\left(y_{k}^{j}\right)\right]
$$

The expected number of failures in the simulated events, conditional on at least one failure occurring, is then

$$
\hat{\mu} \approx \gamma \sum_{j=1}^{54}\left[\sum_{k \in \Delta} F\left(y_{k}^{j}\right) \operatorname{Pr}\left(y_{k}^{j} \mid n^{j}>0\right)\right] .
$$

The simulated mean failure rate calculated using equation (7) is 1.97 , which is close to the value of 1.85 estimated directly from historical observations and lies within the corresponding confidence interval $(1.34,2.38)$.

We also computed upper and lower bounds on this estimate, corresponding to the fragility function confidence region (the shaded area shown around the solid curve in Figure 2). This uncertainty range for the simulated failure rate is between approximately 1.7 and and 2.4, which encloses the central estimate derived from the historical failure data and is similar to, but slightly narrow than, the confidence interval about the historical mean value. 


\section{Network-scale risk analysis}

The above analysis will be extended and combined with estimates of the consequences of bridge failures developed by [19] for combinations of bridge failures, which may occur within any of the events generated within the MCS.

This will enable the estimation of expected bridge failure rates in equation (7) to be extended to assess the expected consequences, over the whole network, of bridge scour failure in terms of disrupted passenger journeys.

\section{References}

1. Kirby, A.M., Roca, M., Kitchen, A., Escarameia, M. and Chesterton, O.J. (2015). Manual on scour at bridges and other hydraulic structures, $2^{\text {nd }}$ edition, Report C742, CIRIA, London, 320 pp.

2. Kattell, J. and Eriksson, M. (1998). Bridge Scour Evaluation: Screening, Analysis, and Countermeasures, United States Department of Agriculture Forest Service, Technology \& Development Program, 7700-Transportation Systems, Report 9877 1207-SDTDC, 12pp (http://www.fs.fed.us/eng/structures/98771207.pdf)

3. Rail Safety and Standards Board (2004). Impact of scour and flood risk on railway structures, Infrastructure Integrity (4) Research Theme: Report Number T112.

4. van Leeuwen, Z. and Lamb, R. (2014). Flood and scour related failure incidents at railway assets between 1846 and 2013, JBA Trust Report W134224, Skipton, UK, www.jbatrust.org

5. Melville, B. (1997). Pier and abutment scour: Integrated approach, ASCE Journal of Hydraulic Engineering, 123, 125-136.

6. Melville, B.W. and Chiew, Y.M. (1999). Time Scale for Local Scour at Bridge Piers, ASCE Journal of Hydraulic Engineering, 25, 59-65.

7. Coleman, S.E., Lauchlan, C.S. and Melville, B.W. (2003). Clear-water scour development at bridge abutments, Journal of Hydraulic Research, 41, 521531, DOI: 10.1080/00221680309499997

8. Hong, J-H., Goyal, M.K., Chiew, Y-M., Chua, L.H.C. (2012). Predicting time-dependent pier scour depth with support vector regression, Journal of Hydrology, DOI: 10.1016/j.jhydrol.2012.08.038

9. Department for Transport, Table RAI0101, London, https://www.gov.uk/government/statistical-data-sets

10. Marti-Henneberg, J. (2013). European integration and national models for railway networks (18402010), Journal of Transport Geography, 26, 126138, doi: 10.1016/j.jtrangeo.2012.09.004

11. Haywood, R. (2007). Britain's national railway network: fit for purpose in the $21^{\text {st }}$ century?, Journal of Transport Geography 15, 198-216, doi:10.1016/j.jtrangeo.2006.02.015

12. Bradbrook, K., Waller, S. and Morris, D. (2005). National floodplain mapping: datasets and methods:
160,000 km in 12 months. Natural Hazards, 36, 103 123.

13. Lamb, R., Keef, C., Tawn, J., Laeger, S., Medowcroft, I., Surendran, S., Dunning, P., Batstone, C. (2010). A new method to assess the risk of local and widespread flooding on rivers and coasts, Journal of Flood Risk Management, 3.

14. Porter, K., Kennedy, R. and Bachman, R. (2007). Creating Fragility Functions for Performance-Based Earthquake Engineering, Earthquake Spectra, 23, 471-489

15. Nelder, J.A. and Mead, R. (1965). A simplex algorithm for function minimization, Computer Journal 7, 308-313

16. McCullagh, P. and Nelder, J.A. (1989). Generalized Linear Models, Second Edition, Volume 37, Chapman and Hall/CRC Monographs on Statistics and Applied Probability, CRC Press, 532 pp

17. Heffernan J. E. and Tawn J. A. (2004). A conditional approach for multivariate extreme values. Journal of the Royal Statistical Society, Series B (Statistical Methodology), 66, 497-546

18. Keef, C., Tawn, J., and Lamb, R. (2013). Estimating the probability of widespread flood events. Environmetrics, 24, 13-21

19. Pant, R., Blainey, S.P., Hall, J.W. and Preston, J.M. (2016). Criticality assessment of a national railway network to inform risk and resilience estimation. Risk Analysis, in review. 